\title{
Estimated Fluoride Doses from Toothpastes Should be Based on Total Soluble Fluoride
}

\author{
Maria José L. Oliveira ${ }^{1}$, Carolina C. Martins ${ }^{2, *}$, Saul M. Paiva ${ }^{2}$, Livia M. A. Tenuta ${ }^{3}$ and \\ Jaime A. Cury ${ }^{3}$
}

1 Department of Paediatric Dentistry and Orthodontics, School of Dentistry, Universidade Estadual de Montes Claros (UNIMONTES), Campus Darcy Ribeiro, Vila Mauricéia, Montes Claros, MG 39410-089, Brazil; E-Mail: lagesdeoliveira@gmail.com

2 Department of Paediatric Dentistry, School of Dentistry, Universidade Federal de Minas Gerais (UFMG), Avenida Antônio Carlos 6627, Belo Horizonte, MG 31270-901, Brazil; E-Mail: smpaiva@uol.com.br

3 Department of Physiological Sciences, Piracicaba Dental School, University of Campinas (UNICAMP), Avenida Limeira 901, Piracicaba, SP 13414-903, Brazil; E-Mails: litenuta@fop.unicamp.br(L.M.A.T.); jcury@fop.unicamp.br (J.A.C.)

* Author to whom correspondence should be addressed; E-Mail: carolcm10@hotmail.com; Tel.: +55-31-3409-2398; Fax: +55-31-3409-2470.

Received: 8 October 2013; in revised form: 23 October 2013 / Accepted: 24 October 2013 / Published: 1 November 2013

\begin{abstract}
The fluoride dose ingested by young children may be overestimated if based on levels of total fluoride (TF) rather than levels of bioavailable fluoride (total soluble fluoride-TSF) in toothpaste. The aim of the present study was to compare doses of fluoride intake based on TF and TSF. Fluoride intake in 158 Brazilian children aged three and four years was determined after tooth brushing with their usual toothpaste (either family toothpaste $(n=80)$ or children's toothpaste $(n=78))$. The estimated dose (mg F/day/Kg of body weight) of TF or TSF ingested was calculated from the chemical analysis of the toothpastes. Although the ingested dose of TF from the family toothpastes was higher than that from the children's toothpastes $(0.074 \pm 0.007$ and $0.039 \pm 0.003 \mathrm{mg} \mathrm{F} / \mathrm{day} / \mathrm{Kg}$, respectively; $p<0.05$ ), no difference between types of toothpaste was found regarding the ingested dose based on TSF $(0.039 \pm 0.005$ and $0.039 \pm 0.005 \mathrm{mg}$ F/day/Kg, respectively; $p>0.05)$. The fluoride dose ingested by children from toothpastes may be overestimated if based on the TF of the product. This finding suggests that the ingested dose should be
\end{abstract}


calculated based on TSF. Dose of TSF ingested by children is similar whether family or children's toothpaste is used.

Keywords: fluorides; dentifrices; toothpastes; dental fluorosis; fluorosis risk

\section{Introduction}

The regular use of fluoridated toothpaste has been associated with a decline in dental caries in both developed and developing countries [1,2]. While the benefits of the use of such toothpaste by children and adolescents are well established [3], fluoridated toothpaste is also considered a risk factor for dental fluorosis [4].

Dental fluorosis is caused by the effect of fluoride ingested during the formation of tooth enamel. The severity of this condition depends on the dose ( $\mathrm{mg} \mathrm{F} /$ day/Kg of body weight) to which the child has been subjected [5]. The literature considers a dose of 0.05 to $0.07 \mathrm{mg} \mathrm{F} / \mathrm{day} / \mathrm{Kg}$ to be an acceptable range in terms of adequate caries control and the avoidance of unsightly (moderate) dental fluorosis [6]. Although this value has been extensively used as a reference to estimate the risk of fluorosis from toothpaste or the relative contribution of fluoride intake from toothpaste compared with fluoride intake from drinking water, longitudinal studies have not found a strong association between this dose and the development of dental fluorosis [7,8]. Furthermore, fluorosis is not resultant from the dose of fluoride ingested, but from the fraction absorbed in the gastrointestinal tract (bioavailability).

The amount of bioavailable fluoride in toothpaste depends on the type of fluoride salt and abrasive used in its composition [9-12]. Due to the incompatibility of $\mathrm{NaF}, \mathrm{SnF}_{2}$ and even amine fluorides with calcium-based abrasives, silica $\left(\mathrm{SiO}_{2}\right)$ particles have been employed. In such formulations, all fluoride is chemically soluble [13-15] so as to be effective against the development of caries [16]. However, if ingested during tooth brushing, all fluoride becomes bioavailable and has a systemic effect, which increases the risk of fluorosis [17].

Toothpastes containing calcium-based abrasives, such as calcium carbonate $\left(\mathrm{CaCO}_{3}\right)$ or dehydrated calcium phosphate $\left(\mathrm{CaH}_{2} \mathrm{PO}_{4} \cdot 2 \mathrm{H}_{2} \mathrm{O}\right)$, are formulated using sodium monofluorophosphate (MFP). Although the MFP ion is more compatible than the fluoride ion with abrasives containing $\mathrm{Ca}$, part of the total fluoride in these formulations is insoluble [14,15] and therefore only partially bioavailable [9-11]. When the level of fluoride intake from toothpaste is estimated in children, it is important to take into account the amount of bioavailable fluoride in the formulation. The dose may be overestimated when the total fluoride (TF) declared on the label is considered and the toothpaste contains MFP/Ca-salts. This is extremely relevant in developing countries, where toothpastes containing $\mathrm{MFP} / \mathrm{Ca}$-salts are usually formulated with a higher fluoride concentration than those containing $\mathrm{NaF} / \mathrm{SiO}_{2}[14,18-20]$. If the total soluble fluoride (TSF) in the formulation is used to calculate fluoride intake, both types of toothpaste may be equivalent in terms of fluorosis risk.

In some developing countries, $\mathrm{MFP} / \mathrm{CaCO}_{3}$ formulations with $\mathrm{TF}$ of 1,400 to $1,500 \mu \mathrm{g} \mathrm{F} / \mathrm{g}$ are often used by children in families with a lower socioeconomic status, while $\mathrm{NaF} / \mathrm{SiO}_{2}$-based toothpastes, which usually contain 1,000 to $1,100 \mu \mathrm{g} \mathrm{F} / \mathrm{g}$, are used by children of families with a higher socioeconomic status [21]. While some studies show that family toothpastes (i.e., those used both by children and the 
rest of the family) can contribute to a significantly higher F intake than children's toothpastes (those used exclusively by the children of a family) [22-24], other studies have found divergent results [21,25,26]. However, the majority of the papers cited do not specify the type of fluoride considered for the estimation of $\mathrm{F}$ intake from toothpastes [22-24,26] and only two studies considered F intake based on TSF determined in the chemical analysis of the toothpastes [21,25].

Therefore, the hypothesis of the present study is that the reported dose of fluoride that children ingest from toothpaste is overestimated if the TF of the formulation is considered rather than TSF.

\section{Experimental Section}

\subsection{Ethical Considerations and Sampling}

This study (NCT01568541) received approval from the Human Research Ethics Committee of the Federal University of Minas Gerais, Brazil (protocol \#278/07). All parents/guardians received information regarding the objectives of the study and signed terms of informed consent. The toothpastes taken for analysis were replaced with new toothpastes.

Two hundred eight children aged nine to 48 months attending four private and four public kindergartens in Montes Claros, MG, Brazil, were enrolled in the present study. Forty-nine children were excluded: nine because they used non-fluoridated toothpastes, four because they did not complete the entire data collection process and 36 because they were aged nine to 35 months. Thus, the final sample comprised 159 children aged 36 to 48 months (weight $=18.8 \pm 6.2 \mathrm{Kg}$ (mean \pm standard deviation) and age $=43.4 \pm 4.3$ months (mean \pm standard deviation)).

\subsection{Experimental Design}

Experimental protocol followed design proposed by Guha-Chowdhury et al. [27] The parents/guardians attended a meeting at the kindergarten and brought the toothbrush and toothpaste that the child used at home. The children brushed their teeth as they usually did at home. The amount of toothpaste used was weighed and the amounts of fluoride ingested as total fluoride (TF) and total soluble fluoride (TSF) were calculated based on an analysis of the toothpaste and the TF declared on the label (Figure 1). The toothpastes were classified [21] as: family (those used by everyone in the child's family, mostly $\mathrm{MFP} /$ calcium carbonate containing 1,500 ppm F) or children's (those used exclusively by the child of the family, mostly NaF/silica based containing 1,100 ppm F). The amount of fluoride ingested was multiplied by the frequency of tooth brushing reported by the parents and divided by the child's body weight. The fluoride dose (mg F/day/Kg of body weight) was determined using the concentration of TF declared on the label as well as the TF and TSF found in the analysis of the toothpastes. The doses based on the declared TF, measured TF and TSF were analysed statistically for all toothpastes. Differences among doses based on declared TF, measured TF and TSF were statistically compared for each type of toothpaste (family $(n=80)$ and children's $(n=79))$ and between the two (Figure 1$)$. 
Figure 1. Flow chart of study design.

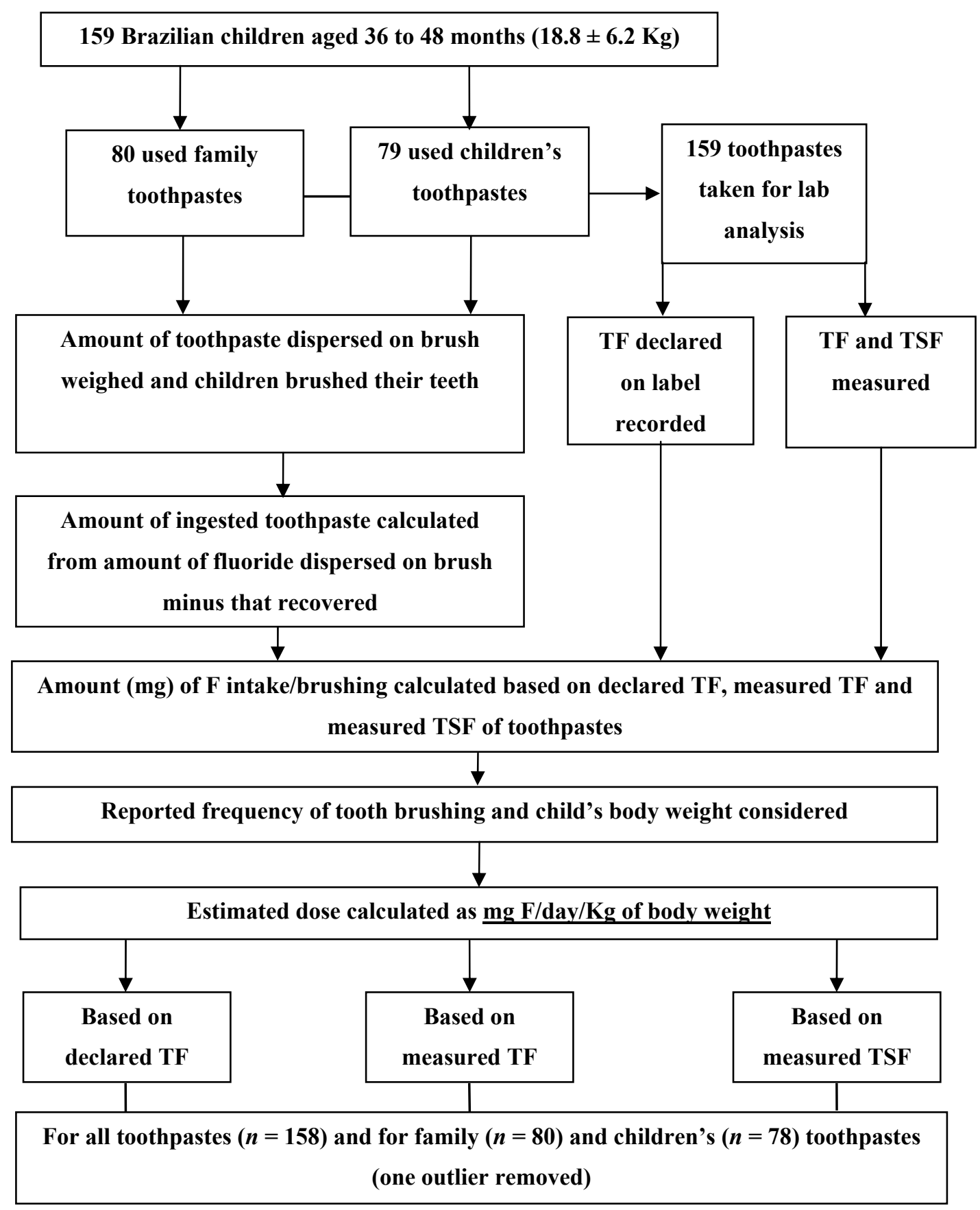

\subsection{Toothpastes Used}

Eighty children used family toothpastes and 79 used children's toothpastes (Figure 1). While most family toothpastes contained $\mathrm{MFP} / \mathrm{CaCO}_{3}$, children's toothpastes contained $\mathrm{NaF} /$ silica. Fluoride concentrations were chemically determined [14] and are displayed in Table 1. The TF concentration in the toothpastes was in agreement with that declared on the label for all toothpastes. However, the TSF concentration found in the analysis of the family toothpastes was lower than the measured or declared TF. TF represents the sum of soluble fluorides (fluoride ion supplied by the NaF and MFP ion) and 
insoluble fluoride bound to the abrasive (usually found in $\mathrm{MFP} / \mathrm{CaCO}_{3}$ toothpaste). TSF is the sum of soluble fluorides (fluoride ion and MFP ion).

Table 1. Concentration (ppm F) of total fluoride (TF) declared on label, TF found in lab analysis and total soluble fluoride (TSF) measured in toothpastes according to type of toothpaste (mean \pm standard deviation; $n$ ).

\begin{tabular}{lccc}
\hline \multirow{2}{*}{ Toothpaste } & \multicolumn{3}{c}{ F concentration $(\mathbf{p p m}$ F) } \\
\cline { 2 - 4 } & Declared TF & Measured TF & Measured TSF \\
\hline Family * $(n=80)$ & $1,424.3 \pm 12.0$ & $1,434.0 \pm 16.2$ & $971.6 \pm 23.4$ \\
Children's ** $(n=79)$ & $1,074.9 \pm 13.1$ & $1,062.3 \pm 12.4$ & $1,070.7 \pm 24.5$ \\
All $(n=159)$ & $1,251.8 \pm 14.6$ & $1,250.5 \pm 18.0$ & $1,020.0 \pm 17.3$ \\
\hline
\end{tabular}

* Used by whole family; ** used only by children.

\subsection{Determination of Fluoride Intake}

Each parent/child pair was taken to the WC of the kindergarten and the child was instructed to brush his/her teeth as he/she usually did at home. The amount of toothpaste dispersed on the toothbrush was weighed $( \pm 0.01 \mathrm{~g})$. The child performed tooth brushing in his/her normal way with or without the aid of his/her parent. No formal instructions were given regarding tooth brushing technique. If the child requested to rinse his/her mouth, the researcher provided purified water for rinsing and a plastic cup to collect the expectorated residue. When the child rinsed his/her mouth and/or spat, the residues were collected in the plastic cup. The toothbrush was vigorously washed with purified water and the residue was collected in the same plastic cup containing the expectorated salivary residue. The mixture, denominated "brushing residue", was homogenised. The volume was measured and an aliquot of $15 \mathrm{~mL}$ of the sample was frozen and stored for the subsequent determination of the fluoride concentration.

Duplicates of $0.25 \mathrm{~mL}$ of this mixture were transferred to assay tubes to which $0.25 \mathrm{~mL}$ of $2 \mathrm{M} \mathrm{HCL}$ were added. The tube was maintained at $45^{\circ} \mathrm{C}$ for $1 \mathrm{~h}$ to hydrolyse the MFP and dissolve any insoluble fluoride bound to the abrasive elements of the toothpaste, if present in the brushing residue. The acid extract was neutralised with $0.5 \mathrm{~mL}$ of $1 \mathrm{M} \mathrm{NaOH}$ and buffered with $1.0 \mathrm{~mL}$ of TISAB [14]. The TF concentration in the sample was determined with an ion-selective electrode and the amount of non-ingested fluoride (mg) was calculated. As the TF in the toothpaste was known, the amount of non-ingested toothpaste was determined from the amount of non-ingested fluoride. The amount of ingested toothpaste was determined by subtracting the amount of non-ingested toothpaste from the amount placed on the toothbrush. Fluoride intake per brushing was determined from the amount of toothpaste ingested and the declared TF, measured TF and TSF. The dose ( $\mathrm{mg} \mathrm{F} /$ day/Kg of body weight) ingested was estimated from the frequency of tooth brushing reported and the weight of the child. All calculations were made using the EXCEL programme (Microsoft, Redmond, WA, USA).

\subsection{Fluoride Analysis}

The analysis of the toothpastes and brushing residues was performed using an ion-specific electrode (Orion 96-09) and an ion analyser (Thermo Scientific Orion, Chelmsford, MA USA), previously calibrated using $\mathrm{F}$ standards (final concentration of $0.0625,0.125,0.25,0.5,1.0,2.0$ and 
$4.0 \mathrm{ppm}$ ) prepared as samples [14]. For each analysis, a linear regression between the F concentration of the standards $(\mu \mathrm{F} / \mathrm{mL})$ and $\mathrm{mV}$ was created $\left(\mathrm{r}^{2}>0.999\right)$ using the EXCEL programme (Microsoft) and used to calculate the $\mathrm{F}$ concentration in the samples. Mean coefficients of variation in duplicate analyses were less than $1 \%$.

\subsection{Statistical Analysis}

Dose data was tested for normality using the Kolmogorov-Smirnov test and Levene's test for variance homogeneity, which demonstrated non-normal distribution and non-homogeneous variance, respectively. The non-parametric Mann-Whitney test $(\alpha=5 \%)$ was used to compare means of $F$ intake between the children's and family toothpastes as well as between declared TF, measured TF and TSF for each type of toothpaste separately and for all toothpastes. The Statistical Package for Social Sciences (SPSS for Windows, version 18.0, SPSS Inc., Chicago, IL, USA) was used for the analysis. One child who used a children's toothpaste was detected as an outlier (dose $=0.7850 \mathrm{mg}$ F/day $/ \mathrm{Kg}$ of body weight) and was excluded from the sample ( $n=158$ children).

\section{Results}

The mean ( \pm standard deviation) weight of the toothpaste used during brushing was $0.55 \pm 0.36 \mathrm{~g}$ for children's toothpaste and $0.59 \pm 0.36 \mathrm{~g}$ for family toothpaste; this difference was non-significant $(p>0.05)$. No statistically significant difference was found in the mean age of the children who used family toothpaste $(43.9 \pm 4.5$ months) (mean \pm standard deviation) and those who used children's toothpaste $(42.8 \pm 4.0$ months) ( $p=0.102$, Mann-Whitney test). No statistically significant difference was found in the mean weight of the children who used family toothpaste $(17.9 \pm 5.2 \mathrm{Kg})$ and those who used children's toothpaste $(19.6 \pm 7.0 \mathrm{Kg})(p=0.111$, Mann-Whitney test $)$. Thus, both groups were homogeneous with regard to age and weight.

Table 1 displays the declared TF, measured TF and measured TSF of the toothpastes (ppm F). Family toothpastes had lower TSF $(971.6 \pm 23.4 \mathrm{ppm} \mathrm{F})$ than declared TF $(1,424.3 \pm 12.0 \mathrm{ppm} \mathrm{F})$ and measured TF $(1,434.0 \pm 16.2 \mathrm{ppm} F)$. Children's toothpastes had similar concentrations of $\mathrm{F}$ for declared TF, measured TF and measured TFS (1,074.9, 1,062.3 and 1,070.7 ppm F, respectively).

Table 2. Estimated dose of fluoride (mg F/day/Kg of body weight) based on total fluoride (TF) declared on label and TF and total soluble fluoride (TSF) measured in analyses according to type of toothpastes (mean \pm standard deviation; $n$ ).

\begin{tabular}{lccc}
\hline \multirow{2}{*}{ Toothpaste } & \multicolumn{3}{c}{ Dose (mg F/day/Kg bw) } \\
\cline { 2 - 4 } & Based on declared TF & Based on measured TF & Based on measured TSF \\
\hline Family * $(n=80)$ & $0.074 \pm 0.007 \mathrm{~A}, \mathrm{a}$ & $0.074 \pm 0.007 \mathrm{~A}, \mathrm{a}$ & $0.039 \pm 0.005 \mathrm{~A}, \mathrm{~b}$ \\
Children's ** $(n=78)$ & $0.040 \pm 0.007 \mathrm{~B}, \mathrm{a}$ & $0.039 \pm 0.003 \mathrm{~B}, \mathrm{a}$ & $0.039 \pm 0.005 \mathrm{~A}, \mathrm{a}$ \\
All $(n=158)$ & $0.057 \pm 0.004 \mathrm{a}$ & $0.057 \pm 0.004 \mathrm{a}$ & $0.039 \pm 0.003 \mathrm{~b}$ \\
\hline * Used by whole family; ** used exclusively by children; Mann-Whitney test for 2 independent samples; \\
Means followed by distinct capital letters differ statistically $(p<0.05)$ between types of toothpastes \\
(columns) and means followed by distinct lowercase letters differ statistically $(p<0.05)$ for each type of \\
toothpaste (lines).
\end{tabular}


No statistically significant differences were found in the estimates of ingested fluoride when calculated using measured TF or declared TF $(p>0.05)$ for all toothpastes or in the separate analyses of family and children's toothpastes (Table 2). However, the dose in the family toothpastes based on TSF $(0.039 \pm 0.005 \mathrm{mg} \mathrm{F} /$ day $/ \mathrm{Kg}$ of body weight $)$ was lower than that based on declared $\mathrm{TF}$ $(0.074 \pm 0.007 \mathrm{mg} \mathrm{F} /$ day $/ \mathrm{Kg}$ of body weight $)$ or measured $\mathrm{TF}(0.074 \pm 0.007 \mathrm{mg} \mathrm{F} / \mathrm{day} / \mathrm{Kg}$ of body weight) $(p<0.05)$. Moreover, the dose ingested from the family toothpastes was higher than that from children's toothpastes when based on declared or measured TF $(p<0.001)$, but the difference was non-significant when based on TSF $(p=0.255)$.

\section{Discussion}

Following the increase in the prevalence of dental fluorosis reported in the USA in the 1980s [28], a number of studies were conducted to evaluate sources of fluoride that contributed to fluoride intake among children at the age of fluorosis risk in addition to the known systemic effect of fluoride in drinking water. However, fluoride intake from toothpaste should consider that the degree of fluoride absorption in the gastrointestinal tract from ingested toothpaste depends on the timing of tooth brushing in relation to mealtimes [29,30], the composition of meals [31] and the formulation of the toothpaste $[10,11]$. Therefore, the failure to consider how much fluoride is absorbed in the gastrointestinal tract may lead to an overestimation of the dose that constitutes fluorosis risk. Indeed, no association has been found between the dose of ingested fluoride and fluorosis $[7,8]$.

The World Health Organization considers $\mathrm{MFP} / \mathrm{CaCO}_{3}$ formulations to be affordable toothpastes for caries control due to their low production cost [32]. The most popular toothpastes used by the children enrolled in this study were the children's toothpaste Tandy ${ }^{\circledR}$ and the family toothpaste Sorriso $^{\circledR}$ and Colgate MPA ${ }^{\circledR}$ (Colgate-Palmolive Industrial Ltda, São Paulo, Brazil) [14].

Besides that, the amount of chemically soluble fluoride in these formulations should be considered when evaluating the risk of fluorosis. The present data show that the dose to which children are subjected can be overestimated when total soluble fluoride (TSF) is not considered in the calculation of F intake (Table 2). Moreover, previous data demonstrate a lower degree of fluoride bioavailability in calcium-based toothpastes [9-12], which are the top selling toothpastes [20].

Since the majority of children's toothpastes are formulated with silica/ $\mathrm{NaF}$, similar concentrations of declared TF, measured TF and TSF were found. In the family toothpastes, mean measured TSF was lower than declared TF and measured TF (Table 1).

As demonstrated in Table 2, if TF declared on the label or measured TF are used to estimate F intake in children, as previous studies have done [22-24,26,33,34], family toothpastes can lead to significantly greater $\mathrm{F}$ intake than children's toothpastes $(0.074$ and $0.039 \mathrm{mg} \mathrm{F} / \mathrm{day} / \mathrm{Kg}$ of body weight, respectively). This alone reaches the upper limit of the dose considered to constitute fluorosis risk $(0.070 \mathrm{mg} \mathrm{F} /$ day $/ \mathrm{Kg}$ of body weight) [6]. However, TF is the sum of TSF and insoluble fluoride in the toothpaste formulation [13-15,35]. When considering measured levels of TSF, no difference in F intake was found between the children's and family toothpastes. Therefore, children using a $\mathrm{MFP} /$ carbonate toothpaste containing around $1,500 \mathrm{ppm}$ of $\mathrm{TF}$ or a NaF/silica toothpaste containing around 1,100 ppm F would be subjected to a "safe" dose if one only considers fluoride intake from a toothpaste, as shown in a previous study [12]. Although the present study did not evaluate gastrointestinal 
absorption, a previous study showed that fluoride salivary excretion is proportionally correlated to fluoride ingestion of TSF but not TF for both formulations [12]. Urinary fluoride excretion is a good indicator for fluoride intake [36], and when aged and fresh toothpastes of these formulations were ingested, one year aged toothpaste MFP/carbonate containing 1,500 ppm of TF had lower urinary fluoride excretion when compared to $\mathrm{NaF} /$ silica toothpaste containing around 1,100 ppm F [12], perhaps due the lower TFS of the formulation after one year of aging [12]. It is important to mention that regardless of the type of toothpaste, toothpastes should contain at least 1,100 ppm F to prevent caries [3], and it is important for paediatric dentists and manufacturers to inform parents regarding the need to use small amounts of toothpaste [21] to minimize F intake.

The present study has three major implications - one methodological, one pragmatic in terms of home toothpaste use and one social in terms of public health and clinical practice: (1) TSF should be considered the methodological measure of $F$ intake from toothpaste in children, as intake may be overestimated when TF is used; (2) It is impractical for each member of a family to use a different specific fluoride toothpaste due to the risk of fluorosis and the whole family can benefit from the use of a family toothpaste with $\mathrm{MFP} / \mathrm{CaCO}_{3}$ even if it contains $1,500 \mathrm{ppm} \mathrm{F}$, balancing the benefits and risks; (3) $\mathrm{MFP} / \mathrm{CaCO}_{3}$-based toothpastes are considered by the World Health Organization to be affordable toothpastes due to their low production costs [32]. These toothpastes are often used by children in families with a lower socioeconomic status, whereas $\mathrm{NaF} / \mathrm{SiO}_{2}$-based toothpastes usually contain 1,000 to $1,100 \mu \mathrm{g} \mathrm{F} / \mathrm{g}$ and are the choice in families with a higher socioeconomic status in both developing [21] and developed countries [37].

\section{Conclusions}

Total Soluble Fluoride (TSF) should be considered for the measure of $F$ intake from toothpaste in children, as intake may be overestimated when Total Fluoride (TF) is considered. Both family toothpastes with $1,500 \mathrm{ppm} \mathrm{MFP} / \mathrm{CaCO}_{3}$ and children's toothpastes with $1,100 \mathrm{ppm} \mathrm{NaF/silica} \mathrm{lead} \mathrm{to} \mathrm{a} \mathrm{similar}$ dose of ingested fluoride (TSF) in young children.

\section{Acknowledgments}

The authors would like to thank Waldomiro Vieira Filho for his help with the fluoride analysis. This study received financial supported from the Brazilian fostering agencies FAPEMIG, CAPES and PRPq/UFMG (Pró-Reitoria de Pesquisa da UFMG).

\section{Conflicts of Interest}

The authors declare no conflict of interests. Jaime A. Cury occasionally acted as a consultant for Colgate/Palmolive in Brazil and the Brazilian Ministry of Health during the study period.

\section{References}

1. Bratthall, D.; Hansel-Petersson, G.; Sundberg, H. Reasons for the caries decline: What do the experts believe? Eur. J. Oral Sci. 1996, 104, 416-422. 
2. Cury, J.A.; Tenuta, L.M.; Ribeiro, C.C.; Paes Leme, A.F. The importance of fluoride dentifrices to the current dental caries prevalence in Brazil. Braz. Dent. J. 2004, 15, 167-174.

3. Marinho, V.C.; Higgins, J.P.; Logan, S.; Sheiham, A. Topical fluoride (toothpastes, mouthrinses, gels or varnishes) for preventing dental caries in children and adolescents. Cochrane Database Syst. Rev. 2003, 4, doi:10.1002/14651858.CD002782.

4. Wong, M.C.; Glenny, A.M.; Tsang, B.W.; Lo, E.C.; Worthington, H.V.; Marinho, V.C. Topical fluoride as a cause of dental fluorosis in children. Cochrane Database Syst. Rev. 2010, 1 , doi:10.1002/14651858.CD007693.pub2.

5. Fejerskov, O.; Manji, F.; Baelum, V. The nature and mechanisms of dental fluorosis in man. J. Dent. Res. 1990, 69, 692-700.

6. Burt, B.A. The changing patterns of systemic fluoride intake. J. Dent. Res. 1992, 71, 1228-1237.

7. Martins, C.C.; Paiva, S.M.; Lima-Arsati, Y.B.; Ramos-Jorge, M.L.; Cury, J.A. Prospective study of the association between fluoride intake and dental fluorosis in permanent teeth. Caries Res. 2008, 42, 125-133.

8. Warren, J.J.; Levy, S.M.; Broffitt, B.; Cavanaugh, J.E.; Kanellis, M.J.; Weber-Gasparoni, K. Considerations on optimal fluoride intake using dental fluorosis and dental caries outcomesA longitudinal study. J. Public Health Dent. 2009, 69, 111-115.

9. Forsman, B.; Ericsson, Y. Fluoride absoption from swallowed fluoride toothpaste. Commun. Dent. Oral Epidemiol. 1973, 1, 115-120.

10. Roldi, C.R.; Cury, J.A. Flluoride metabolism after ingestion of dentifrice. Rev. Gaúcha Odontol. 1986, 34, 425-427, (In Portuguese).

11. Drummond, B.K.; Curzon, M.E.; Strong, M. Estimation of fluoride absoption from swallowed fluoride toothpastes. Caries Res. 1990, 24, 211-215.

12. Falcão, A.; Tenuta, L.M.; Cury, J.A. Fluoride gastrointestinal absorption from $\mathrm{Na}_{2} \mathrm{FPO}_{3} / \mathrm{CaCO}_{3}$ - and $\mathrm{NaF} / \mathrm{SiO}_{2}$-based toothpastes. Caries Res. 2013, 47, 226-233.

13. Giacaman, R.A.; Carrera, C.A.; Munoz-Sandoval, C.; Fernandez, C.; Cury, J.A. Fluoride content in toothpastes commercialized for children in Chile and discussion on professional recommendations of use. Int. J. Paediatr. Dent. 2013, 23, 77-83.

14. Cury, J.A.; Oliveira, M.J.; Martins, C.C.; Tenuta, L.M.; Paiva, S.M. Available fluoride in toothpastes used by Brazilian children. Braz. Dent. J. 2010, 21, 396-400.

15. Carrera, C.A.; Giacaman, R.A.; Munoz-Sandoval, C.; Cury, J.A. Total and soluble fluoride content in commercial dentifrices in Chile. Acta Odontol. Scand. 2012, 70, 583-588.

16. Cury, J.A.; Tenuta, L.M. How to maintain a cariostatic fluoride concentration in the oral environment. Adv. Dent. Res. 2008, 20, 13-16.

17. Ekstrand, J.; Ehrnebo, M. Absoption of fluoride from fluoride dentifrices. Caries Res. 1980, 14, 96-102.

18. Borremans, M.; van Loco, J.; van den Meerssche, P.; Meunier, J.; Vrindts, E.; Goeyens, L. Analysis of fluoride in toothpastes on the Belgian market. Int. J. Cosmet. Sci. 2008, 30, 145-152.

19. Van Loveren, C.; Moorer, W.R.; Buijs, M.J.; van Palenstein Helderman, W.H. Total and free fluoride in toothpastes from some non-established market economy countries. Caries Res. 2005, $39,224-230$. 
20. Ricomini Filho, A.P.; Tenuta, L.M.; Fernandes, F.S.; Calvo, A.F.; Kusano, S.C.; Cury, J.A. Fluoride concentration in the top-selling Brazilian toothpastes purchased at different regions. Braz. Dent. J. 2012, 23, 45-48.

21. Martins, C.C.; Oliveira, M.J.; Pordeus, I.A.; Cury, J.A.; Paiva, S.M. Association between socioeconomic factors and the choice of dentifrice and fluoride intake by children. Int. J. Environ. Res. Public Health 2011, 8, 4284-4299.

22. Puppin Rontani, R.M.; Correa Kassawara, A.B.; Delgado Rodrigues, C.R. Influence of socioeconomic level and dentifrice brand on the oral hygiene habits and the fluoride dentifrice ingestion. J. Clin. Pediatr. Dent. 2002, 26, 319-325.

23. Omena, L.M.; Silva, M.F.; Pinheiro, C.C.; Cavalcante, J.C.; Sampaio, F.C. Fluoride intake from drinking water and dentifrice by children living in a tropical area of Brazil. J. Appl. Oral Sci. 2006, 14, 382-387.

24. Moraes, S.M.; Pessan, J.P.; Ramires, I.; Buzalaf, M.A. Fluoride intake from regular and low fluoride dentifrices by 2-3-year-old children: Influence of the dentifrice flavor. Braz. Oral Res. 2007, 21, 234-240.

25. Oliveira, M.J.; Paiva, S.M.; Martins, L.H.; Ramos-Jorge, M.L.; Lima, Y.B.; Cury, J.A. Fluoride intake by children at risk for the development of dental fluorosis: Comparison of regular dentifrices and flavoured dentifrices for children. Caries Res. 2007, 41, 460-466.

26. Kobayashi, C.A.; Belini, M.R.; Italiani, F.M.; Pauleto, A.R.; Araújo, J.J.; Tessarolli, V.; Grizzo, L.T.; Pessan, J.P.; Machado, M.A.; Buzalaf, M.A. Factors influencing fluoride ingestion from dentifrice by children. Commun. Dent. Oral Epidemiol. 2011, 39, 426-432.

27. Guha-Chowdhury, N.; Drummond, B.K.; Smillie, A.C. Total fluoride intake in children aged 3 to 4 years-A longitudinal study. J. Dent. Res. 1996, 75, 1451-1457.

28. Szpunar, S.M.; Burt, B.A. Trends in the prevalence of dental fluorosis in the United States: A review. J. Public Health Dent. 1987, 47, 71-79.

29. Ekstrand, J.; Spak, C.J.; Vogel, G. Pharmacokinetics of fluoride in man and its clinical relevance. J. Dent. Res. 1990, 69, 550-555.

30. Cury, J.A.; del Fiol, F.S.; Tenuta, L.M.; Rosalen, P.L. Low-fluoride dentifrice and gastrointestinal fluoride absorption after meals. J. Dent. Res. 2005, 84, 1133-1137.

31. Spak, C.J.; Ekstrand, J.; Zylberstein, D. Bioavailability of fluoride added by baby formula and milk. Caries Res. 1982, 16, 249-256.

32. Petersen, P.E.; Lennon, M.A. Effective use of fluorides for the prevention of dental caries in the 21st century: The WHO approach. Commun. Dent. Oral Epidemiol. 2004, 32, 319-321.

33. Levy, S.M.; Warren, J.J.; Broffitt, B. Patterns of fluoride intake from 36 to 72 months of age. J. Public Health Dent. 2003, 63, 211-220.

34. De Almeida, B.S.; da Silva Cardoso, V.E.; Buzalaf, M.A. Fluoride ingestion from toothpaste and diet in 1- to 3-year-old Brazilian children. Commun. Dent. Oral Epidemiol. 2007, 35, 53-63.

35. Hashizume, L.N.; Lima, Y.B.; Kawaguchi, Y.; Cury, J.A. Fluoride availability and stability of Japanese dentifrices. J. Oral Sci. 2003, 45, 193-199.

36. Martins, C.C.; Paiva, S.M.; Cury, J.A. Effect of discontinuation of fluoride intake from water and toothpaste on urinary excretion in young children. Int. J. Environ. Res. Public Health 2011, 8, 2132-2141. 
37. Zohoori, F.V.; Duckworth, R.M.; Omid, N.; O’Hare, W.T.; Maguire, A. Fluoridated toothpaste: Usage and ingestion of fluoride by 4- to 6-yr-old children in England. Eur. J. Oral Sci. 2012, 120, 415-421.

(C) 2013 by the authors; licensee MDPI, Basel, Switzerland. This article is an open access article distributed under the terms and conditions of the Creative Commons Attribution license (http://creativecommons.org/licenses/by/3.0/). 